\title{
BASES PRELIMINARES PARA UNA PERSPECTIVA HISTÓRICA SOBRE LA INVESTIGACIÓN EN LAS QUILCAS O EL ARTE RUPESTRE PERUANO ${ }^{1}$
}

\author{
GORI TUMI ECHEVARRÍA LÓPEZ \\ Universidad NaCIONAL MAYOR DE SAN MARCoS \\ goritumi@gmail.com
}

\section{RESUMEN}

Este artículo, adaptado de una conferencia, delinea las bases para una historiografía de la investigación en las quilcas o el arte rupestre peruano, usando como base divisoria las principales tendencias teórico-intelectuales que han rodeado su investigación. El texto pone en evidencia cinco grandes etapas de desarrollo respecto al estudio del arte rupestre, que no constituyen un decurso lineal de desarrollo académico continuado, sino una historia fragmentada, caracterizada por momentos de notables avances científicos y al mismo tiempo de marcada regresión intelectual.

Palabras clave: quilca, arte rupestre, historiografía, arqueología, investigación.

\section{Abstract}

This article, adapted from a lecture, outlines the bases for a historiography of the rock art research in Peru, using as division point the main intellectual or theoretical tendencies that have surrounded this investigation. The text highlights five major stages of development regarding the study of rock art, which do not constitute a linear course of a continuous academic development, but a fragmented history characterized by moments of remarkable scientific advances and at the same time of strong intellectual regression.

KeYwoRDs: quilca, rock art, historiography, archaeology, research

1. Ponencia presentada al 'The Second International Rock Art Forum in China and the Annual Meeting of China Rock Art Academy - Primitive Language China Rock Art Exhibition 2015', llevada a cabo del 5 al 6 de Julio del 2015 en el Round Hall of the Museo de la Capital, Beijing, China. 


\section{INTRODUCCIÓN}

Aunque la historia de las quilcas o el arte rupestre se pierde en el pasado arqueológico, es sabido que durante el periodo de conquista y colonia del Perú (S XVI-XIX) estas manifestaciones culturales, al igual que otras expresiones gráficas o artísticas en los Andes, fueron conocidas por los invasores europeos, quienes dejaron algunas descripciones de las mismas en crónicas u otros documentos. No es hasta el siglo XIX, sin embargo, al final de la colonia, en que las quilcas son descritas como un específico fenómeno cultural, siendo consideradas posteriormente como un objeto antiguo de categoría académica. En la actualidad este material es estimado como un bien arqueológico y existe una propensión hacia su descripción y estudio científico.

Desde la colonia, el interés en las quilcas ha variado dependiendo fundamentalmente de las tendencias intelectuales o académicas vigentes, lo que ha generado un marcado contraste en el tipo de observación y el tratamiento de esta reliquia cultural a través del tiempo. Debido a esto, es posible distinguir diversas etapas históricas en la investigación rupestre peruana. No obstante, estas etapas solo describen las principales orientaciones e influencias de esta investigación, las que nunca han llegado a formar corrientes teóricas o metodológicas generales.

La historia de los estudios rupestres en el Perú es un tema intrínsecamente importante para la arqueología, y esta expone su auge y su declive; y pone en perspectiva también el poco valor que las quilcas han tenido para las ciencias del pasado, como la arqueología, la historia, o la historia del arte peruano. No obstante, más de 100 años de investigación en las quilcas del Perú son un referente que hay que ponderar y evaluar para una mejor consideración de la disciplina y del p patrimonio rupestre, y del lugar que le hemos reservado para comprender nuestro propio pasado.

\section{Primera etapa. Aproximación inicial al fenómeno rupestre I (2DA mitad DEL SIGLO XIX - 1925).}

Se caracteriza por el inicio del interés intelectual hacia las quilcas o el arte rupestre. Es un periodo en el que se hacen los primeros reportes publicados sobre el tema, los que estaban orientados a destacar descubrimientos de curiosidades o ruinas antiguas, a lo que se sumaban aproximaciones especulativas sobre las mismas. Una de las aportaciones más notables de este periodo lo constituyen los trabajos de varios intelectuales arequipeños que registraron diversos sitios con petroglifos de la región sur del Perú, adelantando interpretaciones históricas y valorando algunos aspectos técnicos del registro, como el grado de patinación de la roca, por ejemplo. Algunos de estos trabajos pioneros fueron de alto nivel pero no tuvieron la difusión adecuada, por lo que no repercutieron en los estudios históricos o arqueológicos peruanos.

Los autores de los primeros registros rupestres peruanos durante esta época son intelectuales, viajeros ilustrados y personajes de amplia cultura, se pueden mencionar entre otros a: Mariano Eduardo de Rivero (1841), Antonio Raimondi (1874), Sebastián Lorente (1860), Thomas Hutchinson (1873) (Fig. 1), Pablo Patrón (2010[1887]), Max Uhle (2012[1901]), Washington Cano (2010[1919]), José A. Mendoza del Solar (2012[1918]), y Horacio H. Urteaga (2012[1919]).

\section{Segunda etapa. Aproximación InICIAl al fenómEno RUPESTRE II (1925-1940)}

A diferencia de la anterior etapa, en la que los estudiosos provenían principalmente de una tradición de ilustración intelectual y círculos culturales, en esta época las investigaciones rupestres se caracterizaron por estar más vinculadas a las esferas académicas universitarias y a centros de investigación arqueológica. 
Esta es la época en que se realizan los primeros descubrimientos científicos de sitios con quilcas en el Perú, incluyendo los petroglifos de Checta (Fig. 1) -descubierto por Pedro Eduardo Villar Córdova en 1925-, y las líneas de Nazca (Fig. 2) -descubiertas por Toribio Mejía Xesspe en 1926-. Este periodo también se caracteriza porque son arqueólogos los que realizan la mayor parte de los hallazgos y trabajos en sitios con quilcas, lo que, no obstante, no va a cambiar radicalmente la tendencia de los estudios que vienen de la época precedente (enfocada únicamente en la parte gráfica de la evidencia, y en aspectos interpretativos), aunque se puede ver también una ligera sistematización, con perspectivas académicas analíticamente más locales, usando categorías arqueológicas y premisas culturalistas.

Es importante destacar que muchas de las propuestas e interpretaciones sobre los sitios con quilcas, que son todavía usadas en la actualidad, fueron hechas durante esta época, pudiéndose mencionar las que sugieren que estos yacimientos delimitan territorios o poblaciones; que las quilcas fueron hechas en relación a caminos; que los sitios con quilcas o las quilcas constituyen adoratorios o lugares sagrados, o que estos sitios son centros de escritura antigua, entre otros.

Se deben mencionar en esta época a Edmundo Escomel (1934), Toribio Mejía Xesspe (2012[1926]), Luis A. Pardo (1942), Julio C. Tello (2004 [1937]) Luis E. Valcárcel (1925), Pedro E. Villar Córdova (1935), entre otros.

\section{TERCERA ETAPA. LA APROXIMACIÓN TOPONÍMICA (1940-1960)}

La tendencia dominante en la investigación rupestre, durante esta etapa, tiene sus orígenes a fines de la década de 1930, cuando un joven investigador llamado Javier Pulgar Vidal, establece la primera asociación entre la nomenclatura de un lugar, y la existencia de quilcas o arte rupestre (Pulgar 1946). En la década de los cuarenta el mismo Pulgar Vidal se va a constituir en el principal investigador del arte rupestre peruano, a partir de la fundación del Departamento de Investigaciones Toponímicas de la universidad Nacional Mayor de San Marcos, estableciendo técnicamente la relación entre el topónimo quilca y los sitios arqueológicos con arte rupestre en el Perú (Fig. 3); dando lugar así al primer derrotero científico de la investigación en las quilcas o el arte rupestre peruano (Pulgar 1959-1960, UNMSM 1962-1963).

Javier Pulgar basó su trabajo en la hipótesis de que la asociación entre el término y el fenómeno rupestre, está condicionada por la nomenclatura original del fenómeno gráfico y su supervivencia como un topónimo. Durante exploraciones llevadas a cabo en la década del cincuenta Pulgar logró corroborar su hipótesis al verificar la relación en sitios de Lima y Huánuco (Fig. 4) con lo cual la asociación quedó firmemente establecida. De esta manera sabemos ahora el nombre nativo original que se usó en tiempos arqueológicos para describir el fenómeno gráfico en los Andes.

El notable planteamiento de Pulgar tuvo un soporte histórico independiente de parte del historiador sanmarquino Raúl Porras Barrenechea, quien siguiendo un derrotero histórico, usando crónicas, diccionarios y vocabularios del siglo XVI y XVII, concluye que el término "quilca" es una categoría que designa expresión gráfica y escritura. En las propias palabras de Porras:

"No cabe, pues, duda de que los indios pre-hispánicos del Perú tuvieron una palabra especial para denominar los signos escritos y que esta palabra se aplicó más tarde por analogía, a la escritura española y al papel que no conocieron los Incas. Esto no quiere decir que ambos sistemas de escritura fuesen iguales sino que se utilizó en quechua el término lingüístico más próximo o semejante para calificar el invento occidental. También se concluye que la palabra quilca estaba unida a la idea no sólo de signos gráficos sino de signos coloreados o de dibujos y pinturas. La voz Quilca trae de por sí aparejada una representación cromática. Escribir, dibujar, pintar se expresan por una sola palabra: quillca, y esta misma palabra sirve para expresar el lienzo, la tabla o el objeto 
pintado. Cabe, pues, usar la palabra quilca como sinónimo de pictografía en el concepto de los etnólogos modernos". (Porras 1963[1945]).

A partir de los trabajos de Pulgar y Porras, el concepto de "quilca" ha servido de base para la interpretación primaria del fenómeno rupestre en el Perú, a partir de la propia terminología indígena, la cual está vigente en diferentes idiomas nativos del Perú (especialmente en Quechua y Aymara). Quilca puede interpretarse como expresión gráfica, así como el acto de graficar en sí mismo; y a partir del siglo XVI, como "escritura" en el sentido europeo del término

Aunque durante esta época la tendencia en la investigación y el registro rupestre fueron dominados por los estudios toponímicos, también se van a desarrollar importantes descubrimientos y muchas investigaciones independientes. En este sentido, el investigador más destacado es sin ninguna duda Eloy Linares Málaga, quien en 1951 va a descubrir el sitio arqueológico de Toro Muerto en Arequipa (Linares 1960), y desde entonces desarrollará una carrera de sesenta años estudiando las quilcas del Perú. El descubrimiento de Toro Muerto (Fig. 5) constituye el más importante descubrimiento arqueológico de su tipo en los Andes hasta el día de hoy, considerando además que es segundo sitio con quilcas más grande de América (después de Miculla en el Perú) y uno de los más grandes del mundo

\section{Cuarta etAPA. Aproximación EURocentrista-INTERPRETATIVA (1960-2010)}

A partir de la década del sesenta la influencia de los estudios rupestres europeos va a ser contundente en el Perú, desfasando todas las tendencias académicas anteriores y obviando por completo los avances en el campo toponímico. La aproximación eurocentrista se impuso casi como una copia de las investigaciones europeas, valorándose los aspectos interpretativos a ultranza, que fueron derivados de paralelos etnográficos sesgados y de la premisa de primitivismo que ha dominado estos estudios en Europa.

La aproximación eurocentrista se ha utilizado principalmente en las investigaciones que combinaron excavaciones arqueológicas en sitios líticos utilizando una base determinista y criterios evolucionistas. Una de las consecuencias de esta aproximación fue la dependencia intelectual de Europa en los estudios rupestres y el deterioro de la investigación hasta llegar a niveles de especulación pura sin ningún fundamento científico.

Fueron los arqueólogos los que impusieron esta aproximación a los estudios rupestres, destacando Augusto Cardich en Lauricocha (1964), Máximo Neyra en Sumbay (1968), Toribio Mejía Xesspe en Monte Calvario - Catache (1968) y Jorge C. Muelle en el famoso sitio de Toquepala (1969) (Fig. 6). Entrada la década del setenta esta tendencia se estableció definitivamente, a la que se sumó la aproximación artístico-historicista de parámetros evolucionistas. El reputado e influente Dr. Jorge C. Muelle, ejemplifica elocuentemente la forma de considerar las quilcas que se impuso en esta época; cuando describe las quilcas de Toquepala, el Dr. Muelle señala:

"Todos los rasgos, en general, configuran los patrones del Paleolítico Superior. Temas y tratamiento sorprenden por su parecido con el arte europeo. El punteado y esas misteriosas líneas paralelas en una de las pinturas de Toquepala (grupo B) recuerdan los "blasones" y puntuaciones de Lascaux. Pero es el arte levantino español más bien que el franco-cantábrico el que se evoca inevitablemente. Falta la grandiosidad, tamaño y nobleza descriptiva de la escuela auriñaco-perigordiense. (...) Muestra un esquematismo naturalista como el estilo de Levante; aun el dinamismo de las escenas y el alargado torso de los personajes trae a la memoria el arte iberoafricano." (Jorge C. Muelle 1969: 195) 
No obstante la tendencia dominante, el Dr. Eloy Linares Málaga siguió desplegando una carrera seria en la investigación rupestre. Esta se centró en aspectos tipológicos, y análisis arqueológicos-culturalistas, destacando claramente la definición de los cuatro tipos convencionales de arte rupestre peruano (Linares 1973) (Fig. 7), y así como la definición y contextualización de nuevos tipos de quilcas, como el arte mobiliar de tradición rupestre, descubierto en el sur del Perú en la época precedente.

Hay que mencionar que durante esta etapa se han publicado la mayor parte de las investigaciones rupestres nacionales, aunque sin perspectivas científicas, salvo muy raras excepciones. Es la época en que, debido a la falta de rigurosidad académica y resguardo legal, las quilcas se popularizaron entre aficionados o personas sin preparación académica adecuada, demeritando la investigación, y logrando finalmente que esta pierda importancia académica. La carencia de una perspectiva crítica y científica, y el incremento del empirismo aficionado ha resultado en la escalada del iconocentrismo y en la destrucción del patrimonio rupestre en una escala sin precedentes. Muchos sitios con quilcas han sido explorados, disturbados, removidos, excavados e intervenidos sin estudios pertinentes, perdiéndose el potencial para una investigación científica relevante; lo que ha sido hecho incluso por arqueólogos profesionales.

\section{Quinta época. Aproximación técnico científica (2010 - )}

Empieza a partir de la fundación de la Asociación Peruana de Arte Rupestre (APAR) hecha el año 2007, y con este acontecimiento la inclusión e implementación de los estándares científicos en la investigación de las quilcas del Perú. Este emprendimiento tiene como fundamento, además, el rescate de las tendencias originales en la investigación rupestre peruana, entre las que destacan la reincorporación de la premisa toponímica, los estudios tipológicos y culturalistas del Dr. Eloy Linares Málaga, y la inclusión de nuevos paradigmas etnográficos nacionales en estas investigaciones.

Entre los aspectos cualitativos más resaltantes destaca fundamentalmente el cambio en los esquemas teórico-metodológicos de la investigación rupestre, que han progresado desde una tendencia interpretativa a ultranza -derivada de la influencia eurocentrista-, a una que prioriza los aspectos factuales, la definición técnica del objeto, la incorporación de categorías materiales de estudio, y la cronología del material. Este cambio es fundamental, ya que obliga a una aproximación más técnica y científica al fenómeno gráfico de las quilcas o arte rupestre.

Entre los parámetros técnicos introducidos durante esta época se pueden mencionar:

La propuesta de códigos de ética

El replanteamiento epistemológico y la refutación teórica de las antiguas premisas que gobernaban la disciplina en el Perú (falsa premisa de la integridad de la evidencia, de la asociación arqueológica, contemporaneidad, de la explicación formal interpretativa, del iconocentrismo, entre otras)

La definición técnica del fenómeno gráfico, clasificación y su nomenclatura

Las definición de las categorías técnico materiales del fenómeno gráfico (Fig. 8).

La introducción de nuevos parámetros conservativos (a consecuencia de las nuevas categorías analíticas. Se debe estimar toda la evidencia con el mismo valor científico)

La introducción de un glosario universal de términos.

La introducción de la Escala Estándar de IFRAO. 


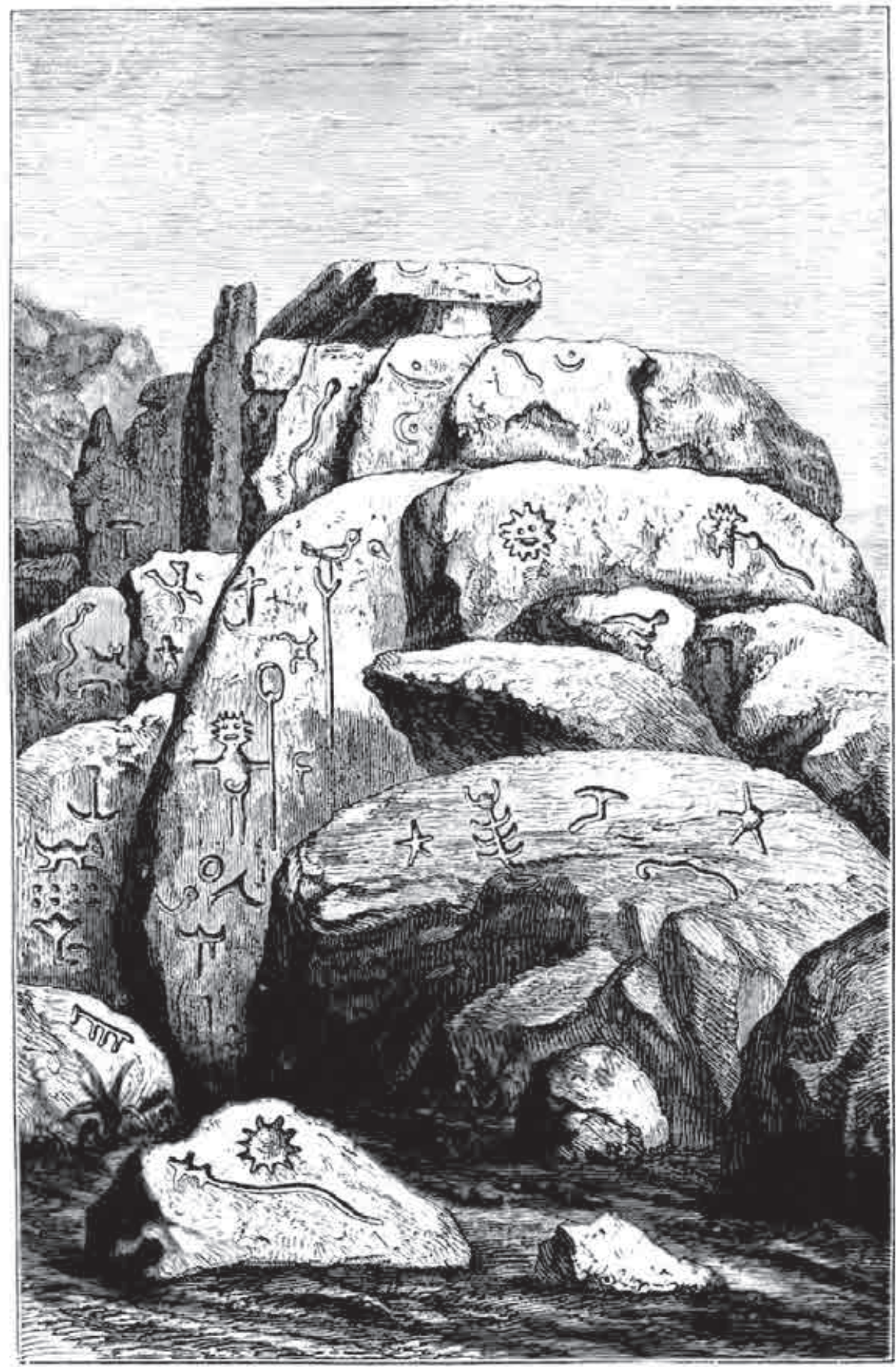

Figura 1. Quilcas del sitio arqueológico Yonan. Tomado de Hutchinson (1873). 


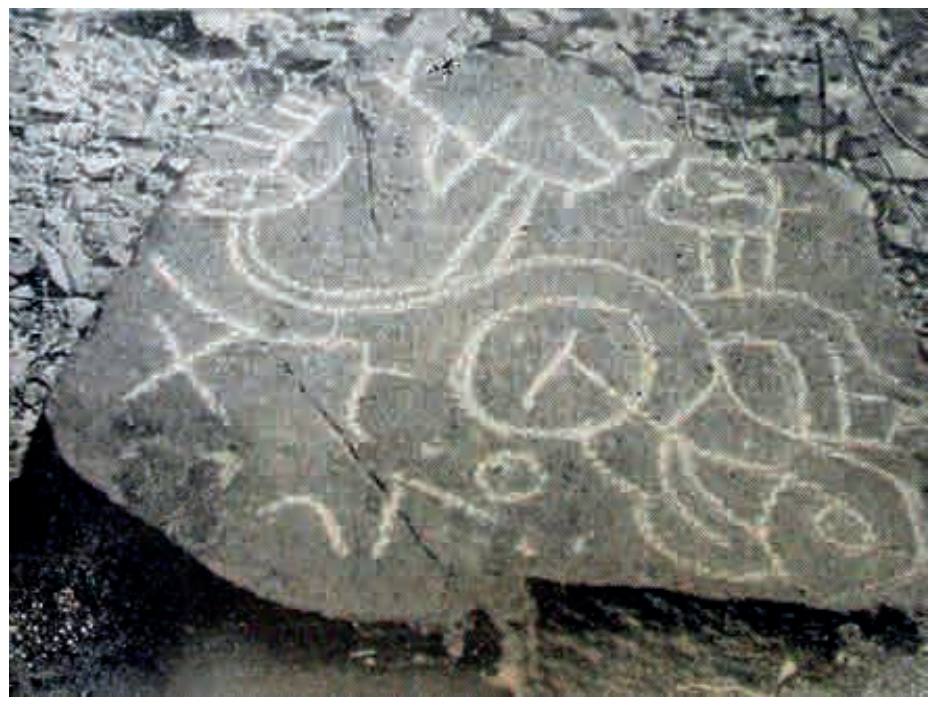

Figura 2. Quilca del sitio arqueológico de Checta, descubierto por Pedro E. Villar Córdova en 1925. Foto tomada de Pedro E. Villar Córdova (1935).

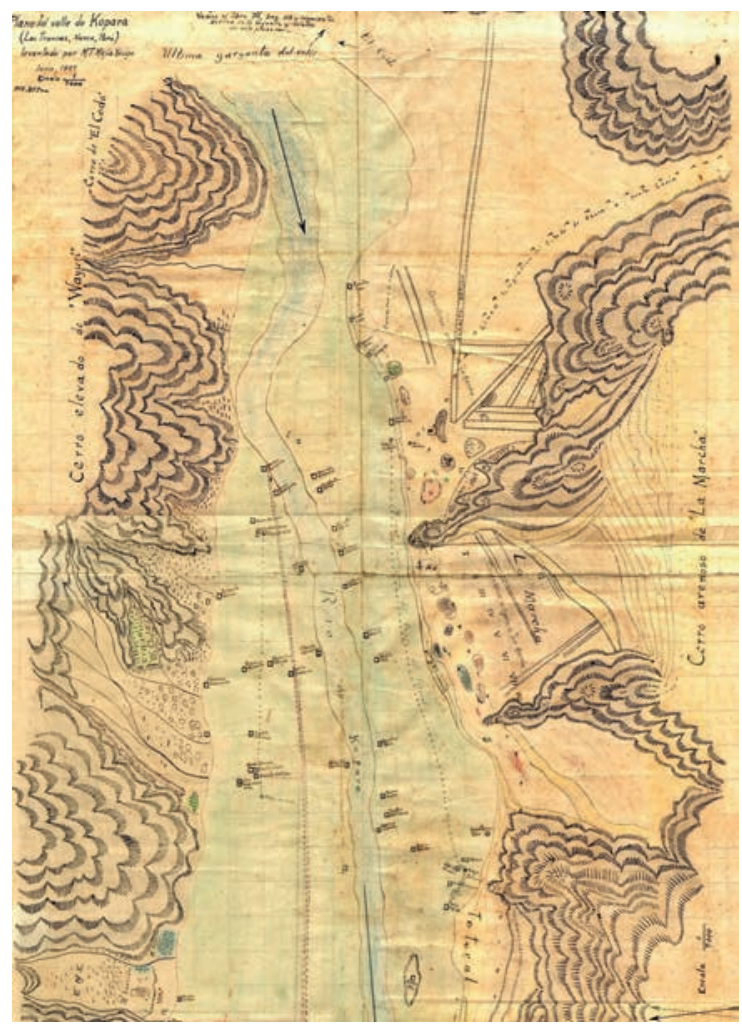

Figura 3. Sección oeste del Plano del valle de Kopara (Las Trancas, Nasca, Perú), levantado por Toribio Mejía Xesspe, Junio, 1927. 


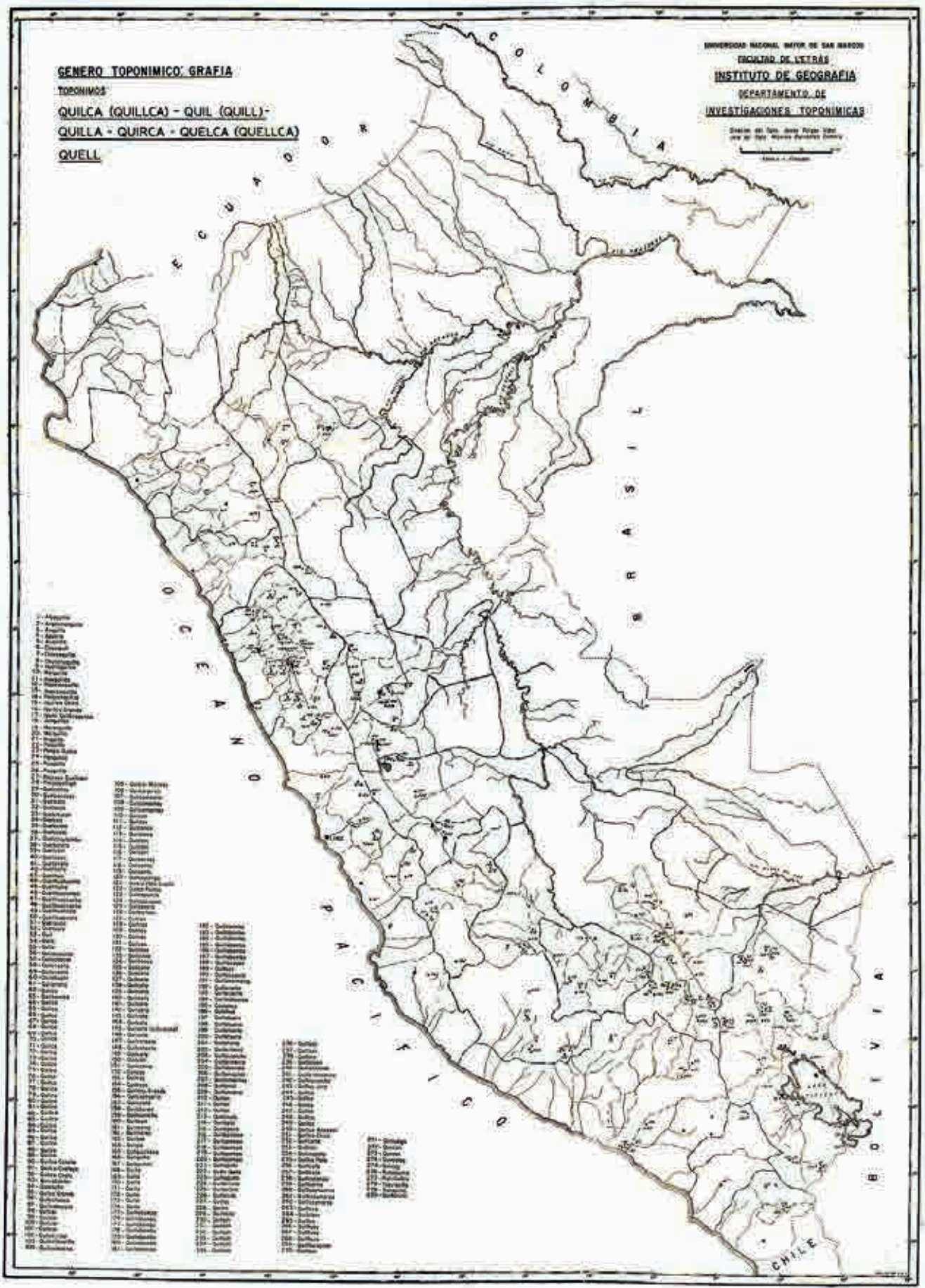

Figura 4. Mapa del Perú, escala 1: 2'000,000, con la ubicación del género toponímico "grafía". Departamento de Investigaciones Toponímicas. Universidad Nacional Mayor de San Marcos. Tomado de Barrantes (1959-1960). 


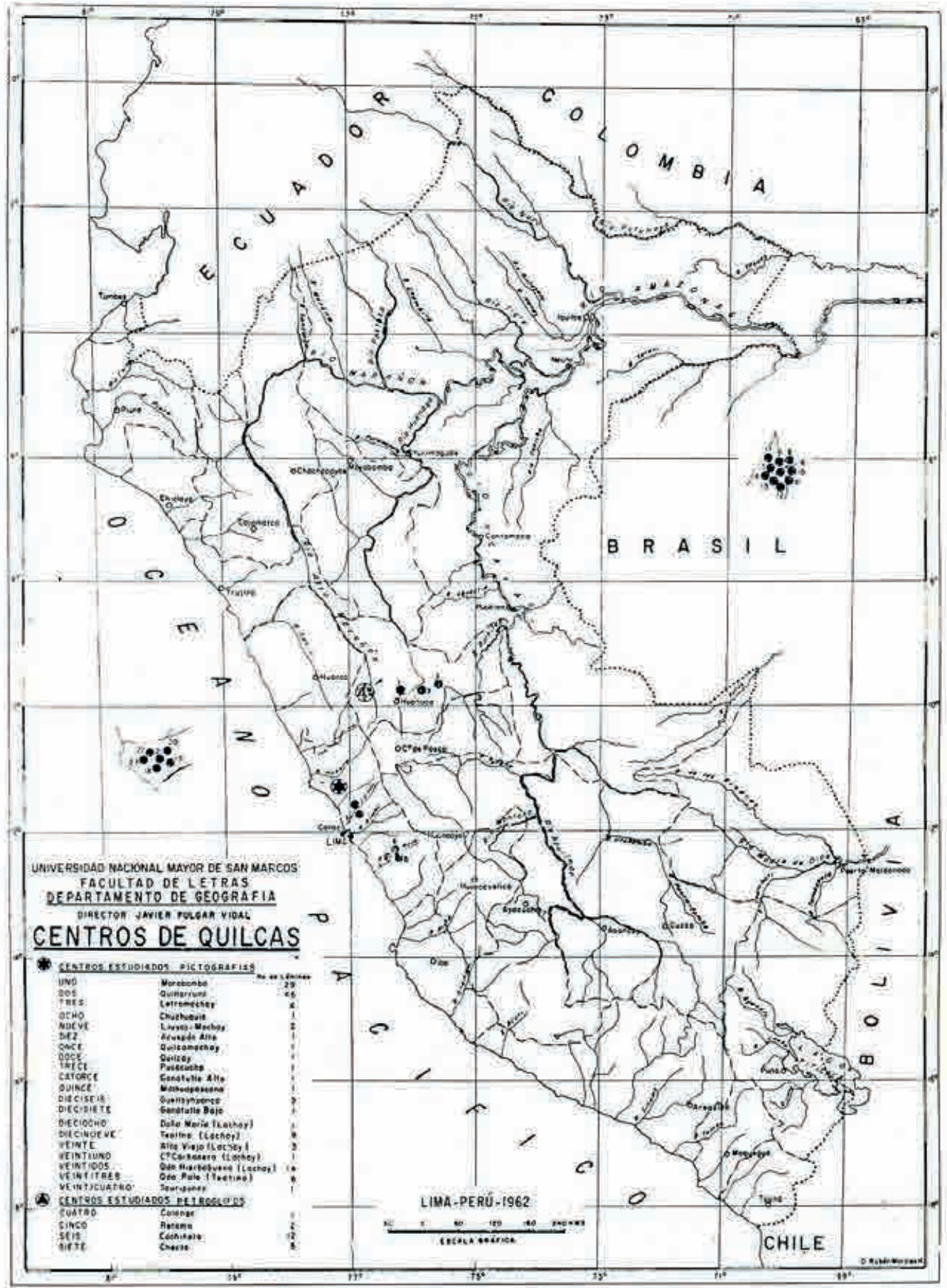

Figura 5. Mapa del Perú con la ubicación de los "Centros de Quilcas" en la costa central y sierra central del Perú. Departamento de Investigaciones Toponímicas. Tomado de Universidad Nacional Mayor de San Marcos (1962-1963). 


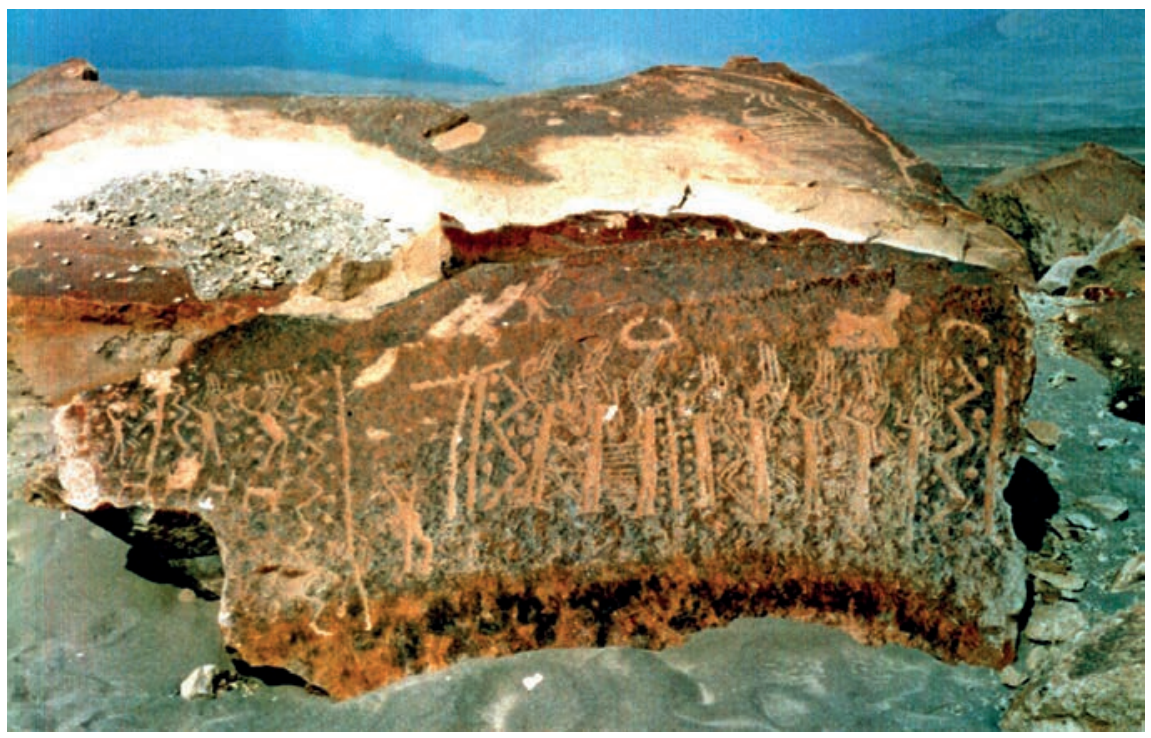

Figura 6. Quilca del sitio arqueológico de Toro Muerto, descubierto por el Dr. Eloy Linares Málaga en la cuenca del río Majes, Arequipa. Foto por Eloy Linares Málaga.

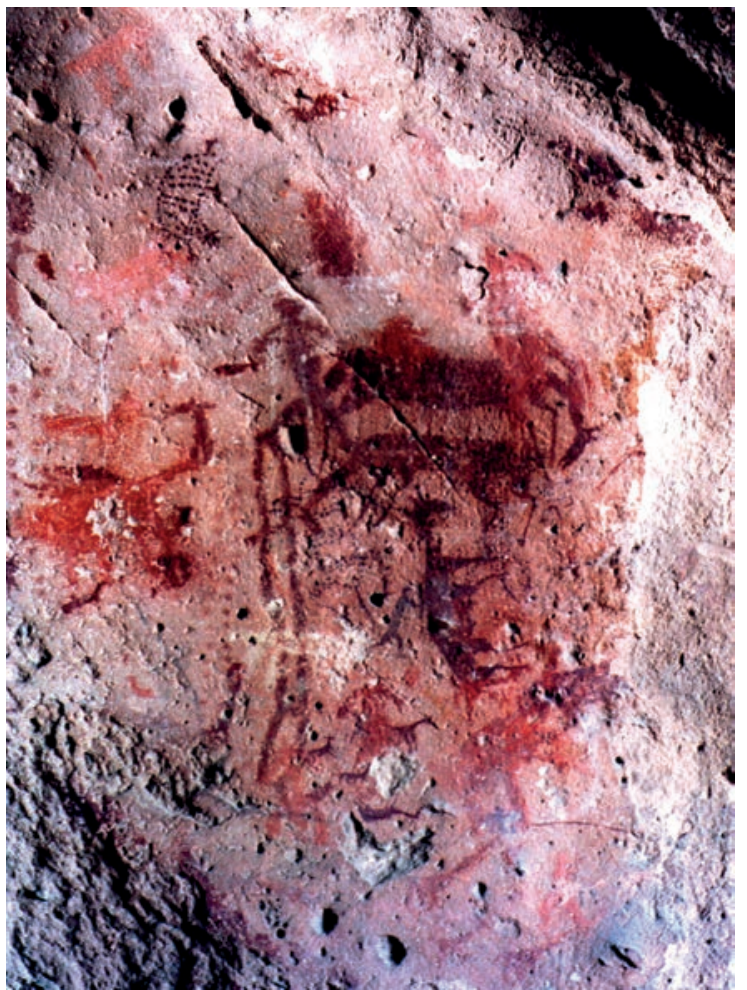

Figura 7. Pictograma de Toquepala, Tacna, estudiado por el Dr. Jorge C. Muelle en la década del sesenta. Foto por Jesús Gordillo. 

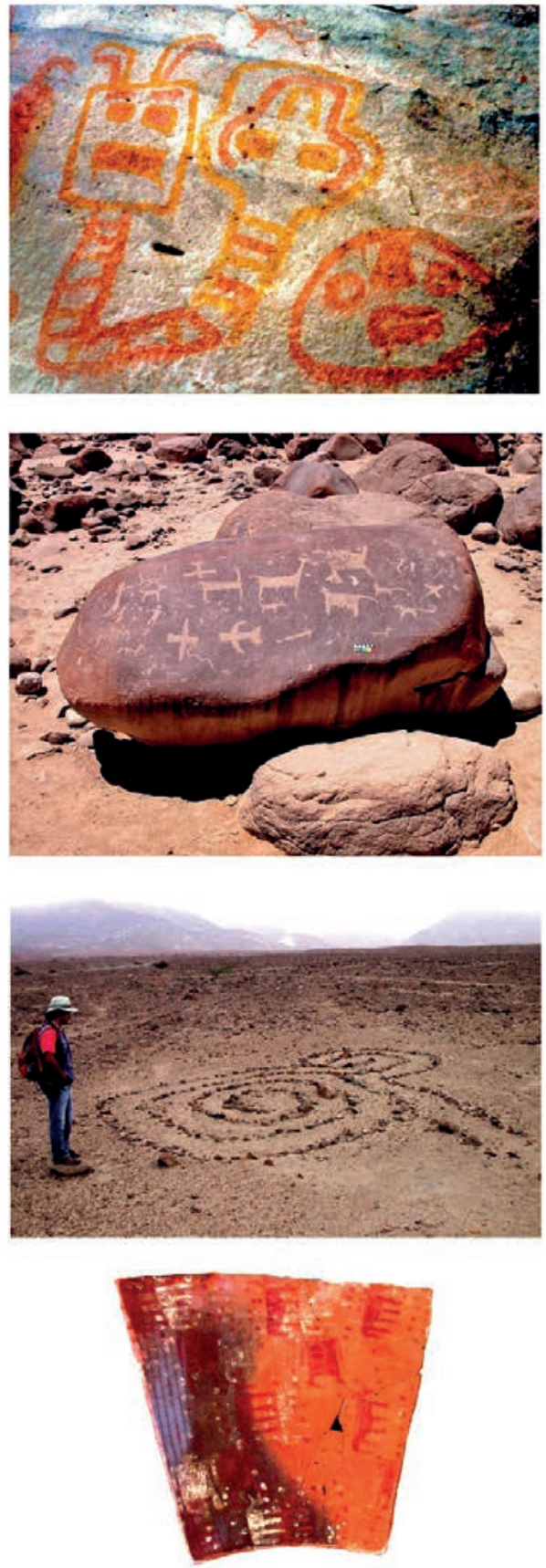

\section{Pintura}

Sitio arqueológico "Quebrada Quilca" Cajamarca

\section{Petroglifo \\ Sitio arqueológico Miculla, Tacna}

\section{Geoglifo}

Sitio arqueológico "Quebrada Santo Domingo", La Libertad 


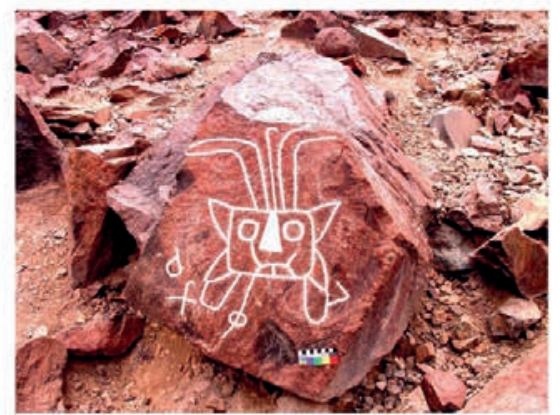

\section{Motivo o imagen}

figurada

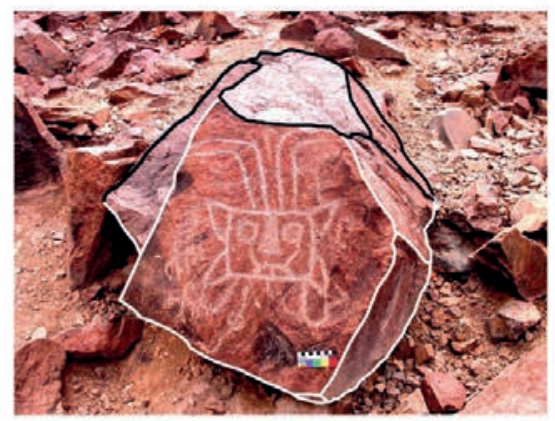

\section{Soporte}

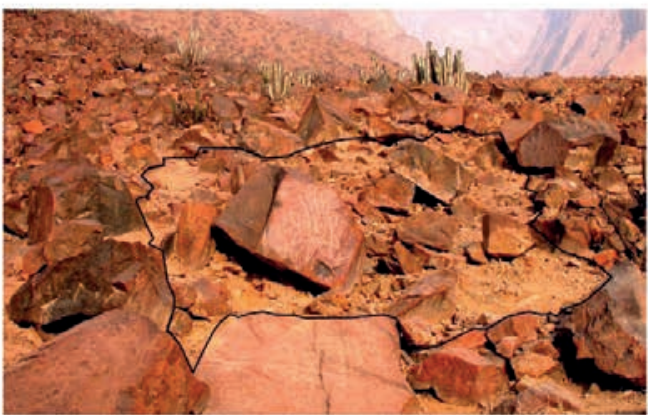

Entorno inmediato

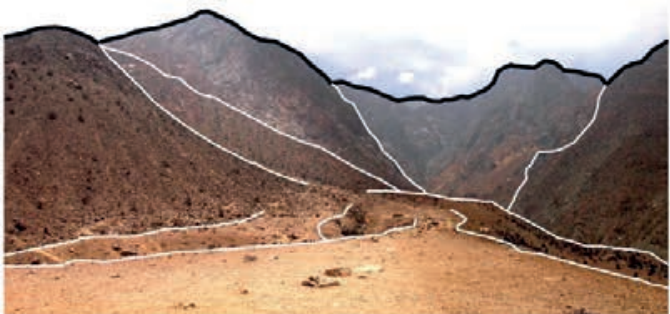

Paisaje 
La introducción de nuevas formas de registro (fotografía RTI, fotogrametría, topografía laser, micro-excavaciones, etc.).

La introducción y adaptación de teorías analíticas (lógica tafonómica, análisis forense, metamorfología, etnografía aplicada, etc.).

La creación de medios especializados para la difusión de los estudios rupestres peruanos (revistas, sitios webs, conferencias, difusión por medios públicos, etc.).

Comunicación académica internacional.

El cambio de perspectiva y la introducción de nuevos estándares científicos, además de la recuperación de las más relevantes contribuciones nacionales al tema, han provocado un cambio radical en el conocimiento de la quilcas o el arte rupestre peruano en los últimos años; y estamos seguros que hemos avanzado más en este tiempo que en todo el lapso de la etapa precedente. Hoy sabemos que los sitios con quilcas en el Perú presentan secuencias muy largas -miles de años de producción gráfica-, y que existe un enorme potencial para comprender localmente la forma en que los antiguos peruanos desarrollaban sus constructos de realidad y su visión del mundo. Sabemos que las quilcas de la yunga de Lima, durante el 3er y 2 do milenos aEC, constituyeron con toda probabilidad, la primera escritura ideográfica de los Andes (Echevarría-López 2013), y sabemos que este fenómeno gráfica, las quilcas, han constituido una expresión social y tradicional que acompañó el desarrollo cultural andino desde sus orígenes hasta que casi acabó abruptamente durante la conquista española.

Sabemos muchas cosas, pero lo que no sabemos es todavía más. Con mucha paciencia estamos reconstruyendo un mundo del que no teníamos casi ningún conocimiento y que por décadas estaba oculto o visto solo desde los ojos de Europa. En este sentido lo que no sabemos es más importante de lo que sabemos. Es justamente lo que no sabemos lo que nos obliga a replantear constantemente, de una manera rigurosa, los estandartes de nuestra propia investigación científica. Es justamente por lo que no sabemos que estamos obligados a preservar y a tratar cada vez con más cuidado las quilcas o el arte rupestre en el Perú. En este sentido debemos estar preparados intelectualmente para enfrentar la protección y la investigación de lo que no conocemos, en la medida que somos capaces de comprender la importancia de esta evidencia, que es la más prístina forma de expresión social de nuestros ancestros, a los que les debemos nuestra propia historia y nuestra propia personalidad.

El reto es concreto, estamos seguros que si avanzamos con perseverancia y disciplina pronto vamos a desarrollar una ciencia sólida que nos va a dar nuevas luces sobre la humanidad, y ese es el objetivo primario de nuestros esfuerzos; la investigación rupestre peruana está encaminada en esa dirección.

\section{BibliografÍA}

BARRANTES ZAMORA, Máximo

1959-1960 "La investigación Toponímica y el hallazgo de los centros pictográficos de la cuenca del río Huallaga”. Informe. Revista del Instituto de Geografía 6: 156-168.

CANO, Washington

2010[1919] “Las ruinas pre-incaicas de Arequipa”. Boletín de Lima XXXII(162): 10-11.

CARDICH, Augusto

1964 Lauricocha. Fundamentos para una prehistoria de los andes centrales. Studia Prehistórica III. Centro Argentino de Estudios Prehistóricos. Buenos Aires. 
ESCOMEL, Edmundo

1934 Tejas peruanas precolombinas destinadas a fines aritméticos. En: XXV Congreso Internacional de Americanistas. La Plata, 1932.

ECHEVARRÍA LÓPEZ, Gori Tumi

2013 "Abstract and geometrical figurative patterns in Peruvian rock art, the first writing in the Americas?" En: Rock Art Research 30(1): 120-124.

2009 “The four material categories of Peruvian rock art". En: Aura Newsletter 26(2): 5-11.

HUTCHINSON, Thomas J.

1873 Two Years in Peru, with Exploration of its Antiquities. Vol. II. London.

LINARES MÁLAGA, Eloy

1960 “Notas sobre los petroglifos de Toro Muerto”. En: Juan Mejía Baca (Ed.), Antiguo Perú, Espacio y Tiempo, pp. 297-299. Lima.

1973 “Anotaciones sobre las cuatro modalidades de arte rupestre en Arequipa (pictografías, Petroglifos, Arte rupestre mobiliar y Geoglifos)”. Anales Científicos de la Universidad del Centro del Perú 2:133-267.

LORENTE, Sebastián

1860 Historia Antigua del Perú. Lima.

MEJÍA XESSPE, Toribio

2012[1926] "Leyenda y detalles arqueológicos del plano correspondiente al valle de "Kopara" (Trancas, Nasca) - Avenidas y trazos ceremoniales”. Boletín APAR 12: 424-428.

1968 "Pintura Chavinoide en los lindes del arte rupestre". San Marcos 19: 15-32.

MENDOZA DEL SOLAR, José A.

2010 [1918] “Los petroglifos de las Calderas”. Boletín de Lima XXXII(162): 15-16.

MUELLE, Jorge $C$.

1969 “Las cuevas y pinturas de Toquepala”. Mesa Redonda de Ciencias Prehistóricas y Antropológicas. PUCP-IRA. Tomo II. pp. 186-196. Lima.

NEYRA AVENDAÑO, Máximo

1968 "Un complejo lítico y pinturas rupestres en la gruta Su-3 de Sumbay". Revista de la Facultad de Letras. 5: 43-75.

PARDO, Luis A.

1942 “Los Petroglifos de La Convención”. Revista del Instituto Arqueológico del Cuzco 10-11: 1-3.

PATRÓN, Pablo

2010[1887]) “Ollantay, por el señor E. Larrabure y Unánue”. En: Boletín de Lima XXXII(162): 9 
PORRAS BARRENECHEA, Raúl

1963 Fuentes Históricas Peruanas. Instituto Raúl Porras Barrenechea, Universidad Nacional Mayor de San Marcos. Lima.

PULGAR VIDAL, Javier

1946 Historia y Geografía del Perú, Tomo I. Las Ocho Regiones Naturales del Perú. Universidad Nacional Mayor de San Marcos, Lima.

1959-1960 "La investigación toponímica y el hallazgo de los centros pictográficos en la cuenca del río Huallaga” - Introducción. En: Revista del Instituto de Geografía 6: 155-156.

RAIMONDI, Antonio

1874 El Perú. Tomo I. Imprenta del Estado, Lima.

RIVERO Y USTARIZ, Mariano Eduardo

1841 Antigüedades peruanas. Primera parte. Lima.

TELLO, Julio C.

2004 Arqueología de Cajamarca: expedición al Marañón - 1937. Fondo Editorial de la Universidad Nacional Mayor de San Marcos, COFIDE. Lima.

UNIVERSIDAD NACIONAL MAYOR DE SAN MARCOS

1962-1963 Primera Exposición Nacional de Quilcas. Facultad de Letras, Departamento de Geografía. Presentación por Javier Pulgar Vidal. Lima.

UHLE, Max

2012[1901] “Los petroglifos de Huancor”. En: Boletín APAR 3(12): 448

URTEAGA, Horacio $\mathrm{H}$.

2010[1924] “Los petroglifos de la Caldera en Arequipa”. En: Boletín de Lima XXXII(162): 12-14.

VALCÁRCEL, Luis Eduardo

1925 “Los Petroglifos del Cuzco”. En: Revista Universitaria 47: 26-29.

VILLAR CóRDOVA, Pedro E.

1935 Las Culturas prehispánicas del Departamento de Lima. 1ra Edición. Auspiciada por la H. Municipalidad de Lima. Lima. 


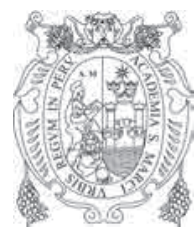

\section{CEPRIM}

SE TERMINÓ DE IMPRIMIR EN EL MES DE ABRIL DE 2017 EN LOS TALLERES GRÁFICOS DEL Centro de Producción Editorial e Imprenta de la Universidad Nacional Mayor de San Marcos LOCAL PRINCIPAL: JR. PARURO 119, Lima 1. TelÉF: 619-7000 ANEXo 6009

E-MAIL: VENTAS.CEPREDIM.UNMSM@GMAIL.COM PÁGINA WEB: WWW.CEPREDIM.COM TIRAJE: XXX EJEMPLARES 